\title{
A construção de argumentos em aulas de ciências: \\ o papel dos dados, evidências e variáveis no estabelecimento de justificativas
}

\section{Building up arguments in the science classroom: the role of data, evidence and variables in the establishment of justifications}

\author{
Lucia Helena Sasseron $^{1}$. Anna Maria Pessoa de Carvalho ${ }^{2}$
}

\begin{abstract}
Resumo: Nosso foco, neste trabalho, recai sobre ações em aulas de ciências que contribuem para a construção de argumentos, sobretudo o trabalho com dados, evidências e variáveis para a construção de justificativas. Nosso referencial teórico principal é o padrão de argumento de Toulmin (TAP-1958/2006). Analisamos a transcrição da gravação de duas aulas de ciências ocorridas em um $4^{\circ}$ ano do Ensino Fundamental. A análise inicial permitiu evidenciar os argumentos construídos coletivamente nestas aulas. A partir deste dado, pudemos identificar de que maneira cada elemento do TAP era construído, considerando, ao mesmo tempo, o trabalho desenvolvido pela professora. Chama a atenção que a construção do argumento ocorre em uma ordem não intuitiva: a professora não parte da construção de uma alegação, mas a alegação constitui-se como decorrência da análise de diversas situações; fornecendo-nos evidências de que o processo por ela utilizado é um processo de investigação sobre dados empíricos.
\end{abstract}

Palavras-chave: Padrão de argumento de Toulmin. Argumentação. Ensino de ciências.

\begin{abstract}
Our aim is analyze actions in science classes that contribute to the construction of arguments, especially working with data, variables and evidence to construct explanations. Our main theoretical framework is Toulmin's argument pattern (TAP-1958/2006). Our data are transcriptions of two recorded science classes which occurred in a fourth year of Elementary School. Initial analysis has highlighted arguments constructed collectively in these classes. From this data, we identify how each TAP element was constructed, considering the teacher's actions. It is noteworthy that the construction of the argument occurs in a non-intuitive order: teacher doesn't start expecting a claim construction, but the claim is a result of the analysis of various situations. Evidence is provided through the investigation of empirical data.
\end{abstract}

Keywords: Toulmin's argument pattern. Argumentation. Science education.

\footnotetext{
1,2 Universidade de São Paulo (USP), Faculdade de Educação, Avenida da Universidade, 308, bloco A, sala 129, Cidade Universitária, CEP 05508-040, São Paulo, SP, Brasil. E-mail: sasseron@usp.br
} 


\section{Introdução}

Muitos pesquisadores na área de Didática das Ciências têm se preocupado com questões ligadas às interações estabelecidas em sala de aula. Estas interações podem estar relacionadas, por exemplo, a ações executadas em materiais didáticos, ao envolvimento com o conteúdo em foco e a interações verbais entre alunos e entre alunos e professores. Nosso foco, neste trabalho, é estudar as interações verbais ocorridas em sala de aula e, de maneira mais específica, analisar como a argumentação é estabelecida em aulas de ciências.

Atualmente, os trabalhos relacionados à construção de argumentos em sala de aula são parte integrante das metodologias de análise de dados nos trabalhos que estudam o ensino e a aprendizagem de Ciências (JIMÉNEZ-ALEIXANDRE; ERDURAN, 2007). Aceita esta premissa, encontramos uma vasta produção sobre a importância e a necessidade de se analisarem as interações verbais de sala de aula para se compreender como o ensino e a aprendizagem de conceitos e noções científicas se desenvolvem nestas oportunidades.

Grande parte dos estudos ligados à argumentação em situações de ensino e aprendizagem em ciências utiliza as ideias propostas por Toulmin $(2006)^{3}$ como referencial analítico da estrutura do argumento.

O uso do padrão de argumento de Toulmin (TAP) em grande parte dos trabalhos na linha de argumentação não vem desacompanhado de críticas a respeito das dificuldades encontradas quando do estudo de situações interativas de ensino e aprendizagem em ciências (BRICKER; BELL, 2008; JIMÉNEZ-ALEIXANDRE; ERDURAN, 2007; NIELSEN, 2013; SAMPSON; CLARK, 2008; SASSERON; CARVALHO, 2011a; VIEIRA; NASCIMENTO, 2009). Alguns destes estudos esboçam modificações no padrão de argumento de Toulmin como forma de auxiliar nas análises que realizam (JIMÉNEZ-ALEIXANDRE; BUGALLO RODRÍGUEZ; DUSCHL, 2000; KELLY; DRUKER; CHEN, 1998; SASSERON; CARVALHO, 2011b; VIEIRA; NASCIMENTO, 2009).

No estudo que ora apresentamos, temos como objetivo identificar e analisar como ocorre o trabalho com dados, evidências e variáveis em sala de aula e de que maneira estas informações são trabalhadas por professores até se transformarem em elementos estruturais de um argumento. Não se trata, pois, de propor alterações no padrão de argumento de Toulmin, mas realizar análise complementar à identificação do TAP com o objetivo de entender como informações e dados são trabalhados na construção do argumento.

Com a finalidade de sintetizar e trabalhar com nosso objetivo, para o presente trabalho, pretendemos responder à seguinte pergunta de pesquisa: a partir da identificação de argumentos construidos em sala de aula, como ocorreu o trabalho com dados, evidências e variáveis para a construção de argumentos em aulas de ciências?

\section{Algumas ideias sobre linguagem e argumentação}

Partimos do pressuposto de que as interações verbais são fator contribuinte para uma compreensão mais geral dos processos de aprendizagem das ciências.

\footnotetext{
${ }^{3} \mathrm{O}$ livro foi publicado originalmente em inglês, no ano de 1958. A edição consultada e estudada é uma versão em português, publicada em 2006.
} 
Estudando textos científicos, Lemke (1998) observa que diversas formas de linguagem se combinam com o objetivo de que haja uma comunicação mais eficaz. O autor afirma que a linguagem é uma prática social e, por isso, ao construirmos significado, recorremos sempre a gestos, ações e elementos próprios de nossa cultura. Neste contexto, Lemke (1998) destaca que há diversas formas de se combinarem informações e relacioná-las e, portanto, diversas formas possíveis de se construir conhecimento. Ele lembra, ainda, que mesmo que haja diferentes maneiras de se conceberem noções para um mesmo conhecimento, a "cultura é livre para produzir novas restrições a estas combinações” (LEMKE, 1998, p. 2, tradução nossa).

A preocupação com a linguagem também aparece em Jiménez-Aleixandre e Díaz de Bustamante (2003) com o foco no trabalho de sala de aula. Os autores dão destaque à ideia de que a linguagem não é unívoca e que diferentes pessoas podem atribuir significados diferentes a uma mesma palavra. Assim, os autores defendem um ensino de Ciências que não seja somente voltado para a exploração de fenômenos, mas no qual haja possibilidade, também, de que a argumentação seja desencadeada em aula.

A relação entre a linguagem científica e a argumentação vem sendo amplamente discutida na área (BERLAND; HAMMER, 2012; JIMÉNEZ-ALEIXANDRE; BUGALLO RODRÍGUEZ; DUSCHL, 2000; KELLY, 2008; MCNEILL; PIMENTEL, 2010; SCARPA; TRIVELATO, 2012), evidenciando a possibilidade de estudos de interações discursivas em sala de aula como forma de compreender como e se ocorre o desenvolvimento da linguagem científica e da argumentação neste espaço.

Jiménez-Aleixandre e Díaz de Bustamante (2003, p. 360, tradução nossa, grifo do autor), também atentos a esta relação, explicitam que "por argumentação entende-se a capacidade de relacionar dados e conclusões, de avaliar enunciados teóricos à luz dos dados empíricos ou procedentes de outras fontes".

Conscientes da necessidade de que as interações discursivas ocorram em sala de aula, como expressão da negociação de significados que ali vai sendo construída, nossa atenção neste trabalho, volta-se ao papel de dados, evidências e variáveis que vão sendo explicitadas e construídas, fomentando, ao mesmo tempo, a construção de ideias que podem ser estruturadas na forma de um argumento tal qual proposto por Toulmin (2006).

Para tanto, entendemos a argumentação como todo e qualquer discurso em que aluno e professor apresentam suas opiniões em aula, descrevendo ideias, apresentando hipóteses e evidências, justificando ações ou conclusões a que tenham chegado, explicando resultados alcançados. O destaque apenas à estrutura do argumento justifica-se pela tentativa de identificar as ações imbuídas em construção do mesmo.

\section{O padrão de argumento proposto por Toulmin}

Conforme mencionamos anteriormente, o padrão de argumento de Toulmin (TAP) é uma das principais referências utilizadas nos trabalhos em Didática das Ciências que se preocupam com a argumentação em situações de ensino.

Toulmin (2006) preocupou-se em estabelecer uma interpretação estrutural da argumentação a fim de perceber de que modo sua validade ou invalidade está relacionada dentro do argumento. $\mathrm{O}$ autor propõe elementos constitutivos básicos da argumentação e as relações existentes entre eles; propõe também que uma asserção feita defende uma alegação. Os 
fatos que apoiam esta alegação são os dados (D) e são os fundamentos com os quais se constrói o suporte à conclusão $(\mathrm{C})$ que se busca apresentar. Deste modo, podemos perceber que a "asserção original apóia-se em fatos apresentados que se relacionem a ela" (TOULMIN, 2006, p. 140).

Como somente os dados não são suficientes para validar a conclusão, são necessárias informações adicionais a fim de relacionar D e C. Estas informações adicionais são, para Toulmin, as garantias (W), e permitem entender como se vincula e se constrói a relação que vai dos dados à conclusão.

Toulmin (2006) ainda se preocupa com casos em que explicitar dado, garantia e conclusão não é suficiente para tornar o argumento aceito. Nestes casos, um qualificador modal (Q) surge e se torna a "força que a garantia empresta à conclusão" (TOULMIN, 2006, p. 153). Segundo o autor, o qualificador modal é o que confere aval à conclusão obtida. No viés oposto, as condições de exceção ou refutação (R) fazem com que a garantia perca força e contestam as suposições por ela criadas.

O último elemento apresentado por Toulmin (2006) dá aval e autoridade às garantias: o apoio (B), que se caracteriza por serem os conhecimentos básicos, advindos de experiências anteriores, que dão suporte à garantia do argumento.

Uma apresentação básica possível do argumento conforme o padrão de Toulmin pode ser representada como: D (dados) assim, Q (qualificadores), C (conclusão), já que W (garantia), considerando que B (apoio), a menos que R (condições de exceção ou refutação).

Estamos certas de que esta estruturação do argumento é algo bastante complexo e refinado. Mas, ao se construir conhecimento científico a partir de dados empíricos (ou, mesmo, hipotéticos), a explanação deve se apresentar de maneira semelhante, uma vez que justificativas são necessárias para dar suporte às conclusões.

\section{Os usos do TAP em pesquisas no ensino de ciências}

Um dos primeiros estudos na área de Ensino de ciências a utilizar o TAP para a análise das interações verbais em sala de aula foi o trabalho de Driver, Newton e Osborne (2000), no qual os autores investigam a construção de argumentos em sala de aula. A partir da ideia original do padrão de argumento de Toulmin, os autores propõem níveis para a avaliação das afirmações proferidas pelos estudantes. Em sua classificação, a afirmação pode variar de valor 0 a 4 a depender da quantidade de justificativas a ela associadas e da presença ou não de refutadores.

Jiménez Aleixandre, Reigosa Castro e Álvarez Pérez (1998), quando da utilização do modelo de Toulmin para a análise da argumentação dos alunos em aulas de ciências, propuseram, primeiramente, uma ampliação ou uma maior caracterização do que Toulmin, em seu modelo, define como dado. Os autores criaram duas categorias específicas para identificação da procedência do dado. Nomearam de dado fornecido (DF) aquele que chega para os alunos, em sala de aula, por intermédio do professor, livro-texto, roteiro do experimento; por dado obtido (DO), os autores se referem àqueles advindos de situações experimentais. Os dados obtidos (DO), por sua vez, podem ser subclassificados em: dado empírico (DE), como no caso dos dados que procedem de uma experiência no laboratório, ou dado hipotético (DH), quando eles são uma construção mental para uma investigação que se tem em plano. 
Em trabalho voltado para a análise de construção de conhecimentos em aula sobre tópicos de genética, Jiménez-Aleixandre, Bugallo Rodríguez e Duschl (2000) entendem o raciocínio científico como um processo de tomada de decisões entre evidências e teorias que exige a construção de argumentos defendendo a escolha tomada. Fica claro, então, que, para os autores, a argumentação é uma estratégia de raciocínio em que dados, evidências e crenças e saberes anteriores, assim como na construção do conhecimento científico, são as bases que conduzem à aprendizagem. Nas considerações finais deste trabalho, os autores mencionam a dificuldade na utilização do TAP para a análise das interações em sala de aula, mas isso fica evidente anteriormente no texto, quando os autores fazem a proposta do uso de operações epistêmicas para analisar os processos pelos quais o trabalho com dados e evidências ocorre até se construir um argumento.

Trabalhos como os de Zohar e Nemet (2002), Erduran, Simon e Osborne (2004) e Jiménez-Aleixandre (2004) propõem alterações mais pontuais e específicas feitas no TAP quando da sua utilização para a análise de situações de ensino e aprendizagem: estas mudanças dizem respeito aos elementos $\mathrm{W}$ (garantia) e B (apoio). Os autores alegam que a distinção entre estes dois elementos na análise das argumentações em situações de ensino é tarefa difícil e, neste sentido, adotam a justificativa como sendo a intersecção entre estes dois elementos.

Analisando os registros escritos produzidos por alunos em aulas de ciências, Krajcik e McNeill (2009) fazem uso das ideias de Toulmin, mas também apresentam alterações no formato original do TAP. Estes autores propõem um estudo da construção do argumento levando em consideração as evidências que suportam uma conclusão e o raciocínio utilizado para apoiar a conclusão construída. Krajcik e McNeill (2009) consideram a possibilidade da presença de refutadores, mas eles são encarados como um contra-argumento.

Em trabalhos anteriores, também encontramos dificuldades no uso do TAP para análise de argumentos construídos em aulas de ciências (SASSERON; CARVALHO, 2008, 2011a, 2011b). Nestes estudos temos utilizado não apenas a estrutura de argumento proposta por Toulmin para a análise da construção de argumentos em sala de aula: a partir do trabalho de 2008, propusemos indicadores de AC, com os quais é possível identificar o envolvimento dos alunos com a investigação e a discussão de temas científicos. Os indicadores de AC auxiliam na análise de como um argumento, oral ou escrito, é produzido em sala de aula, conciliando este uso com a análise da estrutura do argumento, por meio do TAP.

Estudos como os acima destacados mostram esforços contínuos na compreensão da construção de argumentos em situações didáticas. Em específico, no trabalho que ora apresentamos, conforme mencionamos anteriormente, pretendemos discutir o trabalho realizado ao longo de discussões sobre temas das ciências em que dados, evidências e variáveis são analisados para a construção de argumentos.

Partimos do entendimento de que dados são informações obtidas em experiências concretas: podem ser experimentos manipuláveis que geraram dados empíricos, e, também, podem ser discussões previamente estabelecidas em que ideias foram construídas e, as mesmas, agora, serão utilizadas como dados. As variáveis vão sendo identificadas no processo de análise dos próprios dados e de situações ponderadas no estudo deles. As evidências também são informações obtidas por meio de experiências prévias, mas o que as diferencia dos dados é o fato de não serem diretamente observáveis: existe a necessidade de um estudo sobre os dados existentes para se obterem as evidências. 


\section{Analisando a construção de argumentos em sala de aula}

Para estudar a pergunta de pesquisa exposta no início deste trabalho, parece-nos fundamental realizar a análise em dois passos: (a) inicialmente, a análise e identificação de argumentos que tenham sido construídos conjuntamente em aula e, tendo esta informação, (b) as ações desempenhadas para transformar dados, evidências, hipóteses e variáveis em elementos constituintes dos argumentos construídos.

\section{Sobre os dados desta pesquisa}

Os dados que ora serão analisados provêm da gravação em vídeo da implementação da sequência de ensino investigativa intitulada "Navegação e Meio Ambiente". A turma em que as gravações ocorreram correspondia ao $4^{\circ}$ ano do Ensino Fundamental, de uma escola pública estadual, tendo trinta alunos com idades entre nove e dez anos no momento da gravação. As aulas foram registradas em duas câmeras que eram manuseadas por dois pesquisadores. A professora que ministrou as aulas é formada em Pedagogia e, à época, tinhaoito anos de experiência em salas de aula dos anos iniciais do Ensino Fundamental. Ela tinha experiência anterior na implementação de atividades investigativas em sala de aula e conhecia toda a sequência de ensino, já que participou do grupo de elaboração da mesma.

Professora e pais e responsáveis pelos alunos foram informados sobre a coleta de dados e objetivos da pesquisa, e assinaram termos de concessão de imagem e áudio para tal fim. Já no processo de transcrição das falas, todos os nomes foram alterados para manter preservada a identidade de alunos e professora.

\section{A sequência de ensino implementada}

A partir do tema "Navegação e Meio Ambiente", ao longo das aulas são abordados problemas relacionados, confluindo discussões sobre tópicos de Ciência, Tecnologia, Sociedade e Meio Ambiente.

A sequência de ensino inicia com uma atividade de conhecimento físico (CARVALHO et al., 1998), a partir do qual os alunos são instigados a resolverem o problema de construir um barquinho em folhas de alumínio capaz de transportar grande número de peças metálicas sem afundar.

Após isso, dá-se início a pesquisas e discussões sobre a história da navegação e meios de transportes aquáticos. Junto a isso, é apresentada, aos alunos, a ideia de água de lastro como forma de garantir estabilidade às embarcações.

De maneira informativa, os alunos tomam contato com o fato de que a água de lastro pode causar a introdução de espécies de outros hábitats. Para apoiar estas discussões, os alunos têm o apoio a partir da experiência com o jogo "Presa e Predador", em que a dinâmica das populações é evidenciada a partir da análise de dados obtidos ao longo de rodadas de

\footnotetext{
${ }^{4}$ Atividade adaptada do livro Subsídios para implementação de biologia para o $2^{\mathbf{o}}$ grau. São Paulo: CECISP-CENP, 1980. v. 1, p. 45-47.
} 
brincadeira similar a um "pega-pega". Cada personagem do jogo representa um papel: planta, tapiti e jaguatirica; e os alunos participam representando um destes seres vivos, alterando ou não sua representação a depender da dinâmica do jogo. Ao longo de rodadas, dados são coletados e, após serem colocados em tabela, é possível discutir a dinâmica das populações e a estreita relação existente entre os diferentes seres vivos personagens do jogo.

Com este mote, foi possível discutir, em sala de aula, temas que variaram de fenômenos científicos e adventos tecnológicos que possibilitaram melhorias à sociedade e ao modo de vida, até questões e preocupações ambientais suscitadas devido à intervenção humana.

Vale mencionar que a sequência de ensino foi proposta por integrantes do grupo do Laboratório de Pesquisa e Ensino de Física da Faculdade de Educação da Universidade de São Paulo (LaPEF), e que os textos utilizados nas aulas em sua implementação foram produzidos para este fim, considerando a faixa etária dos alunos que o leriam e o ano escolar em que estivessem neste momento.

\section{As aulas analisadas}

Em outros estudos, outras aulas desta mesma implementação foram analisadas. Com o foco no processo de alfabetização científica dos alunos, encontramos evidências de que os alunos participam deste processo identificando elementos para tal afirmação a partir da análise das discussões orais estabelecidas em sala de aula (SASSERON; CARVALHO, 2008) e a partir da análise dos registros gráficos produzidos ao término das mesmas (SASSERON; CARVALHO, 2010).

A escolha pelas aulas 6 e 9 se deu apenas porque, nestas oportunidades, foram discutidos conhecimentos que, respectivamente, se relacionam mais diretamente a ideias da Física e a ideias da Biologia, e, portanto, não nos prendemos a apenas uma disciplina, visto que se trata de uma abordagem sobre ciências.

\section{Aula 6}

Nesta aula, os alunos trabalham uma atividade ligada à flutuação dos corpos, mais especificamente, as condições essenciais para a manutenção da estabilidade de uma embarcação. A atividade central desta aula é a leitura e discussão do texto "Mantendo navios na água", em que o lastro é apresentado como um advento para garantir a estabilidade de embarcações. Ocorreu imediatamente após a aula em que os alunos trazem para a sala de aula imagens de uma pesquisa sobre diferentes embarcações, com as quais discutem, com seus colegas, as semelhanças e diferenças entre as embarcações retratadas nas figuras.

Cada aluno da turma recebeu uma cópia do texto e a leitura do texto foi feita em voz alta pela professora. A cada parágrafo ou a cada nova informação, a leitura era interrompida e iniciava-se discussão com a turma como forma de esclarecer ideias ou ponderar novas informações. A análise desta aula permitiu que identificássemos a construção do seguinte argumento:

\section{Argumento construído na aula 6}

TAP1: Desde que há diferentes tipos de embarcações para diferentes funções, já que a finalidade está associada ao formato da embarcação, considerando que um cargueiro transporta 
muita carga e é largo, um transatlântico transporta muitas pessoas e é longo, uma canoa transporta poucas pessoas e é pequena, assim, a distribuição de carga está diretamente relacionada à constituição física da embarcação.

\section{As interações verbais ocorridas em sala de aula}

O início da aula 6 é marcado pelo cuidado da professora em abordar com os alunos características associadas à constituição física das embarcações e de que modo elas se relacionam com a estabilidade das mesmas. Esta discussão culmina com a construção do TAP1. Ainda que muitas possam ser as variáveis intervenientes para a estabilidade de uma embarcação, para este nível de ensino e nesta aula, será discutida a relação entre formato e função de uma embarcação. O primeiro trecho desta discussão pode ser identificado no Quadro 1.

Quadro 1. Transcrição dos trechos 17 a 28 da aula 6

\begin{tabular}{|c|c|}
\hline Turno & Fala transcrita \\
\hline 17 & $\begin{array}{l}\text { Professora: E o que que vocês notaram de diferente nas embarcações que vocês estavam } \\
\text { trabalhando ontem. [chamando a atenção de uma aluna] Raquel! O que foi que vocês viram de } \\
\text { diferente? [pausa. Só um aluno tem a mão levantada] Só o Luciano?! [outros alunos levantam as } \\
\text { mãos] Igor! Vamos lá! }\end{array}$ \\
\hline 18 & $\begin{array}{l}\text { Igor: Porque assim: um tinha, um tinha vela e o outro não tinha; um era de aço e o outro era de } \\
\text { madeira. }\end{array}$ \\
\hline 19 & $\begin{array}{l}\text { Professora: [concordando] Ah! O material então: um tinha vela, o outro não tinha; outro era de } \\
\text { metal, o outro era de madeira. Que mais que vocês viram de diferença? Quem quiser falar, tem } \\
\text { todo o direito de levantar a mão e esperar a sua vez. Vamos lá, Renato! }\end{array}$ \\
\hline 20 & Renato: Um era reto, o outro tinha vela. \\
\hline 21 & Professora: Ah! Uns tinham vela, como o Igor tinha falado, outros, não. Que mais? Raquel. \\
\hline 22 & Raquel: O nosso foi o mesmo barco. Não tem diferença. \\
\hline 23 & $\begin{array}{l}\text { Professora: Ah! O grupo de vocês... Vocês trouxeram o mesmo tipo de embarcação? Então } \\
\text { vocês não conseguiram ver diferença? Então vamos prestar atenção na discussão agora para } \\
\text { vocês verem as diferenças que tinha entre um e outro. Fala, Daniel. }\end{array}$ \\
\hline 24 & $\begin{array}{l}\text { Daniel: É... É... às vezes um barco, é... A parte debaixo dele, a... não tinha a parte do bico, então } \\
\text { ele era só reto. }\end{array}$ \\
\hline 25 & Professora: [concordando] Tá jóia. Edson. \\
\hline 26 & Edson: Tinha um pontudo, outro menos pontudo. \\
\hline 27 & $\begin{array}{l}\text { Professora: [concordando] Outro menos pontudo... E aí tinha uma pergunta naquela folha de } \\
\text { ontem que era assim: por que que existem estas diferenças? Por que que existem as diferenças } \\
\text { de um barco pra outro? Alguém conseguiu responder esta diferença, ontem? Fala, Lucas. }\end{array}$ \\
\hline 28 & Lucas: Um eu uso para pescar, outro eu uso pra transportar pessoas, outro, pra passear... \\
\hline
\end{tabular}

Fonte: elaborado pelas autoras. 
Este primeiro trecho mostra o trabalho da professora em retomar, com os alunos, informações e ideias construídas na aula anterior. Nos turnos imediatamente anteriores, professora e alunos mencionam terem identificado semelhanças e diferenças entre as embarcações representadas nas imagens analisadas. No turno 17, a professora enfatiza a existência de diferenças e pede que os alunos mencionem quais foram estas características diferenciadas entre as imagens analisadas: trata-se de um trabalho inicial sobre evidências que permitam a compreensão das variáveis associadas à estabilidade das embarcações. À sua pergunta, seguem algumas ideias como as esboçadas nos turnos 18, 20, 24 e 26: os alunos falam de características físicas das embarcações e estão, portanto, trazendo à tona dados empíricos que, para esta investigação, serão variáveis importantes do fenômeno em questão. $\mathrm{Na}$ sequência, no turno 27, de posse dos dados trabalhados anteriormente, a professora propõe uma questão em que solicita, aos alunos, a razão para a existência das diferenças citadas. Neste momento, os alunos explicitam evidências sobre o problema, uma vez que as informações trazidas não podem ser confirmadas apenas pela observação direta de uma imagem ou de um objeto. Estas evidências estão associadas à função de embarcações. Assim como as informações trazidas pelos alunos anteriormente com relação ao formato das embarcações, as ideias ligadas à função das embarcações funcionarão como apoio (B) no TAP1.

A discussão tem continuidade com os turnos destacados no Quadro 2.

Quadro 2. Transcrição dos trechos 29 a 38 da aula 6

\begin{tabular}{|c|c|}
\hline Turno & Fala transcrita \\
\hline 29 & Professora: Ah! Então dependia da função que tinha a embarcação, é isso? Que mais? \\
\hline 30 & $\begin{array}{l}\text { Igor: Por causa do peso dos dois. Um tinha que transportar um tipo de coisa, o outro tinha que } \\
\text { transportar outro tipo de coisas. Podia fazer vários tipos de coisas. }\end{array}$ \\
\hline 31 & $\begin{array}{l}\text { Professora: Tá jóia. E qual a diferença, Rogério, de um barco que transporta carga e um barco } \\
\text { que transporta passageiro? }\end{array}$ \\
\hline 32 & $\begin{array}{l}\text { Rogério: O barco que transporta passageiro precisa ser mais alto para carregar as coisas, } \\
\text { bagagens... }\end{array}$ \\
\hline 33 & Professora: [concordando] Hãhã. E os que transportam carga? Como é que eles eram? \\
\hline 34 & $\begin{array}{l}\text { Rogério: Era bem grande assim [faz gestos: as mãos saem do centro e se distanciam, uma } \\
\text { rumando para a esquerda e a outra, para a direita]. }\end{array}$ \\
\hline 35 & $\begin{array}{l}\text { Professora: Bem largo é o que você quer dizer? Vocês viram? Todo mundo que encontrou as } \\
\text { diferenças, percebeu isso que o Rogério falou? Que os barcos de carga, os navios que } \\
\text { transportam carga eles são mais largos; já os que transportam pessoas, os transatlânticos, } \\
\text { os cruzeiros, por exemplo, eles eram mais altos. E por que que precisa ser assim? Daniel. }\end{array}$ \\
\hline 36 & $\begin{array}{l}\text { Daniel: Pra, pra, pro barco que transporta pessoa tem que ser maior pra caber mais pessoas. } \\
\text { E o que transporta carga tem que ser maior, mais largo pra caber mais carga. }\end{array}$ \\
\hline 37 & Professora: [concordando] Pra caber mais carga? Por que, Igor? \\
\hline 38 & $\begin{array}{l}\text { Igor: Por causa que o de, é, o transatlântico, ele precisa ser mais comprido [faz gesto em } \\
\text { formato de cone para cima] para caber todo mundo, que os passageiros têm bastante coisas. } \\
\text { O de carga, ele é mais largo [faz gestos planos da direita para a esquerda] pra gente botar a } \\
\text { carga em cima dele, pra, pra... }\end{array}$ \\
\hline
\end{tabular}

Fonte: elaborado pelas autoras. 
Uma vez que os alunos explicitaram estas ideias, a professora transforma as ideias dos alunos em variáveis a serem analisadas quando diz, no turno 29, que as diferenças dependia[m] da função que tinha a embarcação, e pergunta aos alunos sobre o que mais poderia influenciar na estabilidade; e logo na sequência, quando ela complementa a discussão fazendo uma pergunta que coloca em contraste as evidências e dados já explicitados: "E qual a diferença, Rogério, de um barco que transporta carga e um barco que transporta passageiro?” (t. 31).

Nos turnos 30, 32 e 34, as respostas dos alunos mostram a construção de relações entre formato e função, ou seja, relações entre variáveis do problema, e estas informações servirão como garantias (W) do TAP1. Esta construção da garantia está bastante clara na fala de Rogério que se inicia no turno 32: "O barco que transporta passageiro precisa ser mais alto para carregar as coisas, bagagens...”; e continua com o auxílio fornecido pela pergunta da professora sobre como seriam as embarcações destinadas a transportar carga, para o qual Rogério completa: "Era bem grande assim" (t. 34). Conforme dito, trata-se da construção de relação entre formato e função da embarcação; e também se evidencia, com estas falas, a extrapolação das ideias anteriormente debatidas e que servem como apoio (B) para a discussão que ora se coloca.

No turno 35, a professora sistematiza as ideias discutidas até este momento. Esta sistematização deixa claro quais as variáveis em jogo e permite que a pergunta feita pela professora leve os alunos a estabelecerem relações causais entre formato e função das embarcações. Estas relações são explicitadas pelos alunos nos turnos 36 e 38, e constituem o par DC (dado-conclusão) do TAP1.

\section{Aula 9}

Ocorreu imediatamente após os alunos terem participado do jogo "Presa e Predador": uma atividade equivalente a um pega-pega em que os alunos são divididos em três grupos, representando, cada um, um ser vivo. Ao longo de rodadas, o professor anota o número de indivíduos de cada espécie para que, em sala de aula, estes dados possam ser analisados e a dinâmica das populações discutida. Nesta aula, um principal argumento pode ser identificado na discussão coletiva:

\section{Argumento construído na aula 9}

TAP2: Desde que existe a necessidade de haver uma boa relação entre o número de presas e de predadores, já que poucas presas levam ao decréscimo do número de predadores; muitos predadores levam ao decréscimo do número de presas, uma vez que o baixo número de presas corresponde à falta de alimento disponível; e o alto número de predadores corresponde à ingestão de maior número de presas, assim, provavelmente, a insuficiência no número de presas pode levar à extinção da espécie predadora, a menos que haja equilíbrio entre presas e predadores.

\section{As interações verbais ocorridas em sala de aula}

Os trechos que apresentamos abaixo ocorreram em momentos intermediários da aula 9. Antes disso, os alunos haviam trabalhado em pequenos grupos para responder a uma série de perguntas diretamente relacionadas ao jogo e aos dados disponibilizados em uma tabela. A discussão com toda a turma teve início após esta primeira análise e a professora 
repassou pergunta por pergunta, discutindo com os alunos as respostas dadas por eles e o porquê destas (Quadro 3).

Quadro 3. Transcrição dos trechos 1 a 21 da aula 9

\begin{tabular}{|c|c|}
\hline Turno & Fala transcrita \\
\hline 1 & $\begin{array}{l}\text { Professora: Bom, vamos lá. Como é que a gente vai fazer então? A gente vai ler as questões, aí } \\
\text { os grupos vão dizer o que acham de cada uma das questões, o que o grupo discutiu, tá bom? } \\
\text { Pra gente não fazer confusão, levanta a mão e eu chamo pessoas do grupo para responder. Tá? } \\
\text { Depois de ter analisado a tabela..., [chamando a atenção de um aluno] Guilherme!, ... que o seu } \\
\text { grupo e o grupo de vocês respondeu sobre que rodada o número de plantas foi maior. Teve } \\
\text { alguma rodada em que o número de plantas foi superior? Davi? }\end{array}$ \\
\hline 2 & Davi: É..., o primeiro. \\
\hline 3 & $\begin{array}{l}\text { Professora: Na primeira rodada, a gente começou com mais planta, não foi? Depois disso, não } \\
\text { ficou maior não, né? }\end{array}$ \\
\hline 4 & Davi [acena negativamente com a cabeça] \\
\hline 5 & Professora: Tá. Todo mundo concorda com o Davi? \\
\hline 6 & Alguns alunos: Siiiim. \\
\hline 7 & $\begin{array}{l}\text { Professora: Grupo do Luciano também concorda? Sim? Tá. Na segunda pergunta em que } \\
\text { rodada o número de plantas foi menor? Fala, Marina. }\end{array}$ \\
\hline 8 & Marina: Foi na quarta rodada. \\
\hline 9 & $\begin{array}{l}\text { Professora: [concordando] Na quarta rodada. Começou com } 10 \text { na quarta rodada, só tinha } 4 \\
\text { plantas. O grupo da Vívian concorda? [concordam com cabeça] Foi isso mesmo? }\end{array}$ \\
\hline 10 & Fábio : Foi. \\
\hline 11 & Professora: Tá. E que rodada começou com o maior número de tapitis? Qual foi, Tadeu? \\
\hline 12 & Tadeu: [lendo] Havia mais quantidade de tapitis na segunda rodada [inaudível] \\
\hline 13 & Edson: É só até aqui, só até aqui, só até aqui. \\
\hline 14 & Professora: Na segunda rodada, aumentou o número de tapitis, foi isso? \\
\hline 15 & Luciano: É. \\
\hline 16 & $\begin{array}{l}\text { Professora: É? E quantas plantas havia nessa rodada em que o número de tapitis foi maior? } \\
\text { Fábio? }\end{array}$ \\
\hline 17 & Fábio: Estava com 7. \\
\hline 18 & Professora: Havia 14 tapitis, mas e quantas plantas haviam nesta rodada? \\
\hline 19 & Fábio: 7 \\
\hline 20 & Professora: 7 plantas. \\
\hline 21 & Fábio: E 24 coisas. \\
\hline
\end{tabular}

Fonte: elaborado pelas autoras. 
Nestes primeiros turnos, percebemos a professora e os alunos listando informações sobre o jogo: são dados empíricos à disposição que estão sendo retomados pela professora de modo a fundamentar o processo de investigação. As perguntas feitas pela professora são exatamente as mesmas respondidas pelos alunos quando do trabalho no pequeno grupo, o que reforça nossa afirmação sobre a retomada de informações já existentes e a organização das mesmas para a análise já em curso.

Nos trechos abaixo, alunos e professora continuam a trabalhar com as perguntas anteriormente respondidas, contudo é importante atentar para que as respostas não estão relacionadas apenas com a obtenção de informações diretamente dos dados transcritos no Quadro 4.

Quadro 4. Transcrição dos trechos 23 a 42 da aula 9

\begin{tabular}{|c|c|}
\hline Turno & Fala transcrita \\
\hline 23 & $\begin{array}{l}\text { Professora: A medida em que o número de tapitis aumenta, o número de plantas, ele } \\
\text { aumenta ou ele diminui? [pausa] Davi. }\end{array}$ \\
\hline 24 & $\begin{array}{l}\text { Davi: É... [pausa] O número de plantas diminuía. Porque quando os tapitis comiam as plantas, } \\
\text { eles, é, elas viravam tapitis. }\end{array}$ \\
\hline 25 & $\begin{array}{l}\text { Professora: Só um minuto, Davi, porque o Edson está falando junto aqui e eu não consegui } \\
\text { entender. Então, aumenta ou diminui o número de plantas? }\end{array}$ \\
\hline 26 & Davi: O número de plantas diminuiu. \\
\hline 27 & Professora: Por quê? \\
\hline 28 & Davi: Porque quando os tapitis comiam as plantas, eles viravam tapitis. \\
\hline 29 & Professora: [concordando] Eles viravam tapitis. E os tapitis se alimentavam de quê? \\
\hline 30 & Júnior: Das plantas. \\
\hline 31 & Professora: [concordando] Das plantas. Na natureza isto acontece também? \\
\hline 32 & Cristiane: Sim. \\
\hline 33 & Vivian: Sim. \\
\hline 34 & $\begin{array}{l}\text { Professora: Se eu tenho um ambiente que tem muitos tapitis e uma quantidade de plantas, os } \\
\text { tapitis, eles vão aumentar a quantidade também das plantas ou eles vão diminuir? }\end{array}$ \\
\hline 35 & Cristiane: Diminuir. \\
\hline 36 & Francisco: Não, aumentar. \\
\hline 37 & Professora: [concordando] Aumentar. \\
\hline 38 & Vivian: Aumentar. \\
\hline 39 & Professora: O número de plantas, com o aumento de tapitis, vai diminuir ou vai aumentar? \\
\hline 40 & Francisco: Aumentar. \\
\hline 41 & Professora: Diminuir. Por que que vai diminuir? \\
\hline 42 & Tadeu: Porque os tapitis vão comer as plantas. \\
\hline
\end{tabular}

Fonte: elaborado pelas autoras. 
Podemos perceber, no turno 23, a professora colocando, aos alunos, uma das perguntas que haviam sido respondidas no pequeno grupo. Respostas à pergunta feita (" $A$ medida em que o número de tapitis aumenta, o número de plantas, ele aumenta ou ele diminui?') exigem uma leitura dos dados em tabela que não é apenas a identificação dos números ali transcritos: trata-se de um trabalho de construção de evidências do fenômeno em questão. Esta construção de evidências ocorre em outros momentos, como, por exemplo, no turno 29 quando a professora faz uma pergunta cuja resposta ancora-se na retomada das regras do jogo que haviam sido discutidas na aula anterior e, supostamente, estão claras para os alunos, uma vez que a atividade foi realizada com bastante êxito, no que diz respeito à sua operacionalização. A pergunta da professora, neste turno 29 , inicia um processo de avaliação de evidências em outras situações. No turno 34, a pergunta feita - "Se eu tenho um ambiente que tem muitos tapitis e uma quantidade de plantas, os tapitis, eles vão aumentar a quantidade também das plantas ou eles vão diminuir?"- leva à construção de hipóteses pelos alunos. Para a resposta a esta pergunta, a própria professora parece demonstrar confusão neste momento: no turno 37 ela concorda com a opinião de Francisco sobre o aumento da população de plantas com relação a uma superpopulação de tapitis, mas, no turno 41, ela ignora a fala do aluno e propõe a resposta correta: "diminuir" o número de plantas em caso de haver muitos tapitis, seus predadores. Ainda que isso tenha ocorrido, sua imposição da resposta correta é amenizada ao colocar em avaliação esta diminuição. Com esta discussão, as hipóteses colocadas em cena poderão ser utilizadas como evidências da dinâmica das populações estabelecida no jogo; e estas respostas terão o papel de apoio (B) no TAP2.

Continuando a discussão apoiada nas perguntas já respondidas pelos pequenos grupos, a turma continua a levantar dados e evidências para a situação em investigação (Quadro 5).

A fala da professora no turno 83 ("Pessoal, olhem a segunda rodada. A população de tapitis, ela estava aumentando, ela estava diminuindo ou ela estava, ou ela tinha alcançado o máximo do que ela podia ter alcançado antes?') leva os alunos a uma análise utilizando dados e evidências à disposição. Falas como a de Luciano, nos turnos 97 e 103, retratam esta análise. Aqui, os dados e evidências destacados anteriormente são usados para responder à pergunta da professora e atuarão como garantia (W) no TAP2. Estas informações são também uma justificativa para o comportamento de flutuação já identificado por eles.

A discussão segue e a professora começa a fazer perguntas que já não estão listadas entre aquelas trabalhadas nos pequenos grupos: são perguntas de extrapolação das ideias já debatidas e servem como avaliação para a análise realizada até aqui (Quadro 6).

A pergunta feita no turno 126 ("Agora vamos pensar diferente. Vamos pensar que a gente tem muita jaguatirica nesse ambiente, o que que vai acontecer?') é claramente uma pergunta para avaliar a construção em curso. A resposta do aluno Igor, no turno 136, sistematiza as ideias debatidas e, ao dizer "Eu acho que vai ser assim: se tiver muita jaguatirica em um lugar, as jaguatiricas vão comer tudo os tapitis e pode entrar em extinção os tapitis, e ai depois as jaguatiricas vão virar tudo planta porque elas não vão ter alimento", percebemos a explicitação do par D-C (dado-conclusão) do TAP2.

Ainda na continuidade desta discussão, mais um trecho merece ser destacado, conforme Quadro 7.

A resposta dada por Luciano no turno 152, mais uma vez, explicita o par D-C do TAP2, mas ela vai além: ao mencionar a necessidade de um suposto equilíbrio e relacionar a 
Quadro 5. Transcrição dos trechos 83 a 103 da aula 9

\begin{tabular}{|c|c|}
\hline Turno & Fala transcrita \\
\hline 83 & $\begin{array}{l}\text { Professora: Pessoal, olhem a segunda rodada. A população de tapitis, ela estava aumentando, } \\
\text { ela estava diminuindo ou ela estava, ou ela tinha alcançado o máximo do que ela podia ter } \\
\text { alcançado antes? }\end{array}$ \\
\hline 84 & Eric: [imitando a professora] Máximo. \\
\hline 85 & Professora: Fala, Davi. \\
\hline 86 & Davi: Tava aumentando. \\
\hline 87 & $\begin{array}{l}\text { Professora: [concordando] Tava aumentando, né? Na segunda. Tava de } 9 \text {, na primeira, passou } \\
\text { pra 14. E lá na última rodada que tava de } 7 \text { jaguatiricas, quantos tapitis tinham? }\end{array}$ \\
\hline 88 & Aluno desconhecido: 9 e 12. \\
\hline 89 & Davi: 9. \\
\hline 90 & Professora: 9 tapitis. E a população de plantas, como é que estava? Na segunda rodada? \\
\hline 91 & Júnior: 7 e 7. \\
\hline 92 & Professora: Tava diminuindo. E na sexta rodada? Tinha...? \\
\hline 93 & Davi: Aumentado. \\
\hline 94 & $\begin{array}{l}\text { Professora: [concordando] Aumentado de novo. Como é que vocês explicam esse resultado? } \\
\text { [pausa] Como é que vocês explicam essa movimentação, essa variação? }\end{array}$ \\
\hline 95 & Breno: Que que é variação? \\
\hline 96 & Professora: Variar, de aumentar, de diminuir. Fala, Luciano. \\
\hline 97 & Luciano: É por causa que um animal, ele nunca sempre vai, ele nunca sempre vai diminuir. \\
\hline 98 & Professora: [pedindo ao aluno para esperar] Luciano. \\
\hline 99 & Guilherme: $E$ isso que eu ia falar. \\
\hline 100 & Professora: [chegando ao grupo] Tudo bem nesse grupo? \\
\hline 101 & Edson: Tudo bem. \\
\hline 102 & Professora: Vocês podem abrir o material, por favor? Obrigada. Desculpa, Luciano, fala. \\
\hline 103 & $\begin{array}{l}\text { Luciano: É por causa que, tipo assim, você tem assim, né? As jaguatiricas, elas... Se elas são } \\
\text { 14, se elas comer mais 14, elas vão virar } 28 \text {. Então não dá pra sempre ficar com o mesmo } \\
\text { número. Ou ela vai aumentar ou ela vai abaixar. Por causa que nem sempre as jaguatiricas vão } \\
\text { comer os tapitis, nem sempre os tapitis vão comer as plantas e nem sempre eles vão deixar de } \\
\text { comer. }\end{array}$ \\
\hline
\end{tabular}

Fonte: elaborado pelas autoras.

necessidade dele para que não ocorra a variação, Luciano está explicitando uma contra-justificativa para as ideias construídas, o que atuará como refutador (R) no TAP. 
Quadro 6. Transcrição dos trechos 126 a 136 da aula 9

\begin{tabular}{|c|c|}
\hline Turno & Fala transcrita \\
\hline 126 & $\begin{array}{l}\text { Professora: [concordando] Vai diminuir bastante. Agora vamos pensar diferente. Vamos pensar } \\
\text { que a gente tem muita jaguatirica nesse ambiente, o que que vai acontecer? }\end{array}$ \\
\hline 127 & Luciano: Elas vão comer muitos tapitis, os tapitis vai diminuir. \\
\hline 128 & Júnior: Diminuir, e as jaguatiricas vai aumentar. \\
\hline 129 & Professora: E o que que acontece com as plantas? \\
\hline 130 & Júnior: Também vão aumentar porque os tapitis não vão comer elas. \\
\hline 131 & $\begin{array}{l}\text { Professora: Porque tem, não tinha tapitis suficientes para comer as plantas daí elas vão } \\
\text { aumentar. Não é isso? }\end{array}$ \\
\hline 132 & Luciano: $\dot{E}$. \\
\hline 133 & Professora: Você acha que é isso, Luciano? \\
\hline 134 & Luciano: É, mais ou menos. \\
\hline 135 & Professora: Que que você acha, Igor? \\
\hline 136 & $\begin{array}{l}\text { Igor: Eu acho que vai ser assim: se tiver muita jaguatirica em um lugar, as jaguatiricas vão } \\
\text { comer tudo os tapitis e pode entrar em extinção os tapitis, e aí depois as jaguatiricas vão virar } \\
\text { tudo planta porque elas não vão ter alimento. }\end{array}$ \\
\hline
\end{tabular}

Fonte: elaborado pelas autoras.

Quadro 7. Transcrição dos trechos 152 a 155 da aula 9

\begin{tabular}{|c|l|}
\hline Turno & \multicolumn{1}{c|}{ Fala transcrita } \\
\hline 152 & $\begin{array}{l}\text { Luciano: É como se fosse um equilíbrio. As plantas vão ter pouco, mas o deles vai ter muito. Aí } \\
\text { se tiver pouca planta, vai dar comida pra poucos tapitis. Os outros vão morrer e vão virar } \\
\text { plantas. Aí vai ter mais plantas, aí o tapiti vai comer. Aí as jaguatiricas vão comer tapiti. É como } \\
\text { se fosse um equilíbrio. }\end{array}$ \\
\hline 153 & $\begin{array}{l}\text { Professora: Você quer dizer que precisa ter equilíbrio nos três. Não pode ter nem muito e nem } \\
\text { pouco de cada um. É isso? }\end{array}$ \\
\hline 154 & \begin{tabular}{l} 
Luciano: É. Senão dá essa variação. \\
\hline 155
\end{tabular} \\
$\begin{array}{l}\text { Professora: [concordando] Por isso que tem essa variação. Muito bem observado. Senão } \\
\text { alguma população acaba sofrendo. }\end{array}$ \\
\hline
\end{tabular}

Fonte: elaborado pelas autoras.

\section{Alguns comentários à guisa de considerações finais}

Nossa análise limitou-se a duas aulas e a um argumento construído em cada uma destas aulas, mas resultados de trabalhos já publicados analisando estes mesmos dados (SASSERON, 2008; SASSERON; CARVALHO, 2008, 2010) nos permitem afirmar que o mes- 
mo caminho foi utilizado por professores ao longo da discussão sobre a investigação de um problema.

Nosso objetivo com este estudo era identificar e analisar como ocorre o trabalho com dados, evidências e variáveis em sala de aula, e de que maneira estas informações são trabalhadas por professores até se transformarem em elementos estruturais de um argumento. Pudemos observar que o trabalho ocorre por meio de perguntas feitas pela professora que envolvem os alunos na discussão e, portanto, promovem participação dos alunos nas interações verbais ocorridas em aula. É interessante perceber que a professora segue um caminho (o mesmo que pode ser observado pelos resultados obtidos com a análise de outras aulas em que a mesma metodologia de ensino foi usada) que se inicia com o trabalho com dados empíricos disponíveis; estes dados são avaliados em outras situações, o que leva à construção de hipóteses pelos alunos e, portanto, ao estabelecimento de evidências que serão usadas na investigação. O trabalho com os dados e as evidências fornece, aos alunos, o apoio (B) do argumento em construção. Além disso, tanto dados empíricos como evidências são postas, na discussão, na condição de variáveis para o problema, e esta análise possibilita a construção de garantias (W) do argumento. A avaliação das garantias é, então, o que permite o estabelecimento de relações entre as variáveis em jogo e, consequentemente, a explicitação do par dado-conclusão (D-C) do argumento, e também das condições-limite para a situação em análise que, neste caso, entra como refutador $(\mathrm{R})$ no padrão de argumento de Toulmin.

O que chama a atenção com esta análise é que a construção do argumento ocorre em uma ordem não intuitiva: a professora não parte da construção da alegação que satisfaria a condição de estabilidade, mas esta alegação constitui-se como decorrência da análise de diversas situações; fornecendo-nos evidências de que o processo por ela utilizado é um processo de investigação sobre dados empíricos.

\section{Referências}

BERLAND, L. K.; HAMMER, D. Framing for scientific argumentation. Journal of Research in Science Teaching, New York, v. 49, n. 1, p. 68-94, 2012.

BRICKER, L. A.; BELL, P. Conceptualizations of argumentation from science studies and the learning sciences and their implications for the practices of science education. Science Education, Hoboken, v. 92, n. 3, p. 473-498, 2008.

CARVALHO, A. M. P. et al. Ciências no ensino fundamental: o conhecimento físico. São Paulo: Scipione, 1998.

DRIVER, R.; NEWTON, P.; OSBORNE, J. Establishing the norms of scientific argumentation in classrooms. Science Education, Hoboken, v. 84, n. 3, p. 287-312, 2000.

ERDURAN, S.; SIMON, S.; OSBORNE, J. TAPping into argumentation: developments in the application of Toulmin's argument pattern for studying science discourse. Science Education, Hoboken, v. 88, n. 6, p. 915-933, 2004.

JIMÉNEZ-ALEIXANDRE, M. P. La catástrofe del prestige: racionalidad crítica versus racionalidad instrumental. Cultura y Educación, Madrid, v. 16, n. 3, p. 305-319, 2004. 
JIMÉNEZ-ALEIXANDRE, M. P.; BUGALLO RODRÍGUEZ, A.; DUSCHL, R. A. Doing the lesson" or "doing science": argument in high school genetics. Science Education, Hoboken, v. 84, n. 6, p. 757-792, 2000.

JIMÉNEZ-ALEIXANDRE, M. P.; DÍAZ DE BUSTAMANTE, J. Discurso de aula y argumentación en la clase de ciências: cuestiones teóricas y metodológicas. Enseñanza de las Ciencias, Barcelona, v. 21, n. 3, p. 359-370, 2003.

JIMÉNEZ-ALEIXANDRE, M. P.; ERDURAN, S. Argumentation in science education: an overview. In: ERDURAN, S.; JIMÉNEZ-ALEIXANDRE, M. P. (Ed.). Argumentation in science education. Dordrecht: Springer, 2007. p. 3-27.

JIMÉNEZ-ALEIXANDRE, M. P.; REIGOSA CASTRO, C.; ÁLVAREZ PÉREZ, V. Argumentación en el laboratorio de física. In: ENCONTRO DE PESQUISA EM ENSINO DE FÍSICA, 6., 1998, Florianópolis. Atas... Florianópolis: SBF, 1998. 01 CD-ROM.

KELLY, G. Inquiry, activity and epistemic practice. In: DUSCHL, R. A.; GRANDY, R. E. Teaching scientific inquiry: recommendations for research and implementation. Roterdam: Sense Publishers, 2008. p. 99-117.

KELLY, G.; DRUKER, S.; CHEN, C. Students' reasoning about electricity: combining performance assessments with argumentation analysis. International Journal of Science Education, London, v. 20, n. 7 , p. $849-871,1998$.

KRAJCIK, J.; MCNEILL, K. L. Designing instructional materials to support students in writing scientific explanations: using evidence and reasoning across the middle school years. In: ANNUAL INTERNATIONAL CONFERENCE GRAND CHALLENGES AND GREAT OPPORTUNITIES IN SCIENCE EDUCATION, 2009, Garden Grove. Disponível em: < http://

www.katherinelmcneill.com/uploads/1/6/8/7/1687518/krajcikmcneill_narst2009.pdf $>$. Acesso em: 26 mar. 2014.

LEMKE, J. Multiplying meaning: visual and verbal semiotics in scientific text. In: MARTIN, J. R.; VEEL, R. (Ed.). Reading science. London: Routledge, 1998. p. 87-113.

MCNEILL, K. L.; PIMENTEL, D. S. Scientific discourse in three urban classrooms: the role of the teacher in engaging high school students in argumentation. Science Education, Hoboken, v. 94, n. 2, p. 203-229, 2010.

NIELSEN, J. A. Dialectical features of students' argumentation: a critical review of argumentation studies in science education. Research in Science Education, Dordrecht, v. 43, n. 1, p. 371-393, 2013.

SAMPSON, V.; CLARK, D. Assessment of the ways students generate arguments in science education: current perspectives and recommendations for future directions. Science Education, Hoboken, v. 92, n. 3, p. 447-472, 2008.

SASSERON, L. H. Alfabetização científica no ensino fundamental: estrutura e indicadores deste processo em sala de aula. 2008. 180 f. Tese (Doutorado em Educação) - Faculdade de Educação, Universidade de São Paulo, São Paulo, 2008.

SASSERON, L. H.; CARVALHO, A. M. P. Almejando a alfabetização científica no ensino fundamental: a proposição e a procura de indicadores do processo. Investigações em Ensino de Ciências, Porto Alegre, v. 13, n. 3, p. 333-352, 2008.

- Uma análise dos referenciais teóricos para estudo da argumentação no ensino de ciências.

Ensaio: pesquisa em educação em ciências, Belo Horizonte, v. 13, n. 3, p. 243-262, 2011a. 
. Construindo argumentação na sala de aula: a presença do ciclo argumentativo, os indicadores de alfabetização científica e o padrão de Toulmin. Ciência \& Educação, Bauru, v. 17, n. 1, p. 97-114, 2011b. Disponível em: <http://www.scielo.br/scielo.php?pid=S151673132011000100007\&script=sci_arttext $>$. Acesso em: 26 mar. 2014.

Escrita e desenho: análise de registros elaborados por alunos do ensino fundamental em aulas de ciências. Revista Brasileira de Pesquisa em Educação em Ciências, São Paulo, v. 10, n. 2, p. 1-19, 2010. Disponível em: <http://revistas.if.usp.br/rbpec/issue/view/4>. Acesso em: 26 mar. 2014.

SCARPA, D. L.; TRIVELATO, S. L. F. A linguagem e a alfabetização científicas: características linguísticas e argumentativas de artigos científicos. Genética na Escola, Ribeirão Preto, v. 7, n. 2, p. 4657, 2012. Disponível em: < http://disciplinas.stoa.usp.br/mod/resource/view.php?id=44318>. Acesso em: 26 mar. 2014.

TOULMIN, S. E. Os usos do argumento. 2. ed. São Paulo: Martins Fontes, 2006.

VIEIRA, R. D.; NASCIMENTO, S. S. Uma proposta de critérios marcadores para identificação de situações argumentativas em salas de aula de ciências. Caderno Brasileiro de Ensino de Física, São Paulo, v. 26, n. 1, p. 81-102, 2009.

ZOHAR, A.; NEMET, F. Fostering students' knowledge and argumentation skills through dilemmas in human genetics. Journal of Research in Science Teaching, New York, v. 39, n. 1, p. 35-62, 2002. 